\title{
Cástulo: investigación arqueométrica y transferencia social
}

\author{
Alberto Sánchez Vizcaíno, David J. Parras Guijarro, Eva M. ${ }^{a}$ Montes Moya | Instituto \\ Universitario de Investigación en Arqueología Ibérica, Universidad de Jaén \\ Marcelo Castro López | Conjunto Arqueológico de Cástulo, Junta de Andalucía \\ José A.Tuñón López, M. ${ }^{a}$ Oliva Rodríguez Ariza | Instituto Universitario de \\ Investigación en Arqueología Ibérica, Universidad de Jaén \\ Manuel Montejo Gámez | Dpto. de Química Física y Analítica, Universidad de Jaén \\ Bautista Ceprián del Castillo, Pilar Amate Espinosa | Instituto Universitario de \\ Investigación en Arqueología Ibérica, Universidad de Jaén \\ Peter Vandenabeele | Dpto. de Arqueología, Universidad de Gante \\ Url de la contribución <www.iaph.es/revistaph/index.php/revistaph/article/view/4251>
}

\section{RESUMEN}

Cástulo: investigación arqueométrica y transferencia social ha sido concebido como un proyecto de investigación arqueométrica de carácter interdisciplinar en el que participan el Instituto Universitario de Investigación en Arqueología Ibérica de la Universidad de Jaén, el Conjunto Arqueológico de Cástulo (Linares, Jaén) y la Universidad de Gante (Bélgica). La importancia patrimonial, histórica y social de Cástulo lo convierte en un entorno ideal para hacer compatibles los objetivos de investigación y difusión. Desde esta perspectiva, en este trabajo se presentan las bases fundamentales del proyecto, la metodología de investigación físico-química y paleoambiental y la estrategia de difusión de los resultados. Los materiales que se someten a análisis son pinturas murales, mosaicos, recipientes cerámicos, carbones y semillas. Por medio de su análisis se obtendrán nuevos datos sobre materias primas, procesos de trabajo, actividades rituales, evolución del paisaje y estrategias de explotación económica que completarán la interpretación de Cástulo y la información disponible para los investigadores y ciudadanos que visiten el conjunto arqueológico.

\section{Palabras clave}

Arqueometría | Conjunto Arqueológico de Cástulo | Iberos | Linares (Jaén) | Patrimonio arqueológico | Romanos | 


\section{CÁSTULO: CONJUNTO ARQUEOLÓGICO E INTERÉS HISTÓRICO}

Tras haber sido delimitada la zona arqueológica de Cástulo, con una superficie superior a las 3.200 ha y distribuida entre los términos municipales de Linares, Lupión y Torreblascopedro (Jaén), la Junta de Andalucía creó el Conjunto Arqueológico de Cástulo (Linares, Jaén) compuesto por el área del poblado y el Museo de Linares, monográfico de Cástulo (DECRETO 261/2011, de 26 de julio).

Se puede descomponer el valor patrimonial de la zona arqueológica de Cástulo en diversos aspectos y características que se han sumado para justificar la creación del conjunto arqueológico. En primer lugar, la amplitud y representatividad de su secuencia temporal y la integridad material tanto de su núcleo central -la ciudad amurallada-, como del territorio inmediato. Además, destaca la extensión y centralidad de la propiedad pública $(69,69$ ha), la larga tradición de aprovechamiento científico y cultural de las ruinas y, en especial, su actualización en los últimos sesenta años en torno al Museo Arqueológico de Linares, monográfico de Cástulo. Por último, como importante singularidad, se aprecia que la zona arqueológica coincide con un enclave medio-ambiental excepcionalmente conservado, en la que las posibles afecciones son controladas a raíz de la inscripción de la delimitación de la zona arqueológica en el Catálogo General del Patrimonio Histórico de Andalucía (CASTRO, 2015).

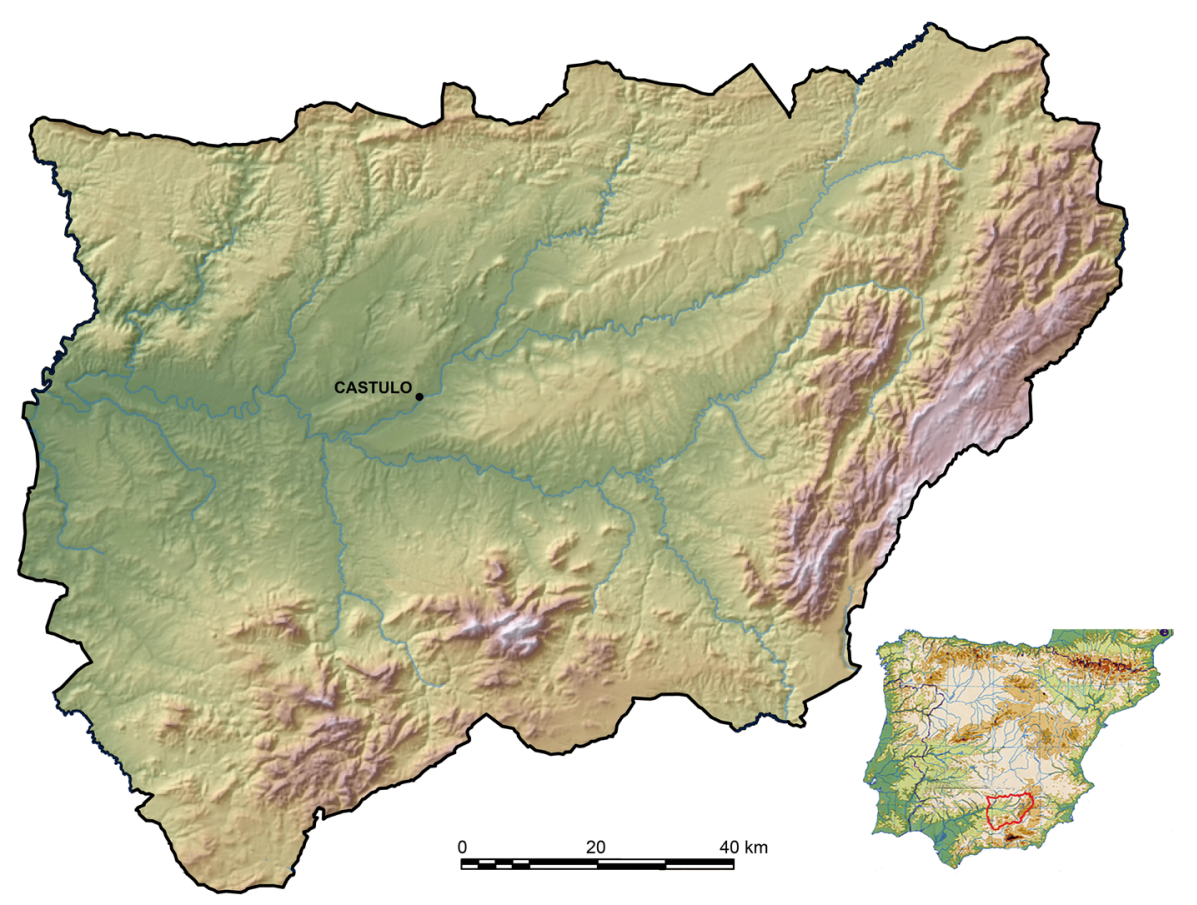




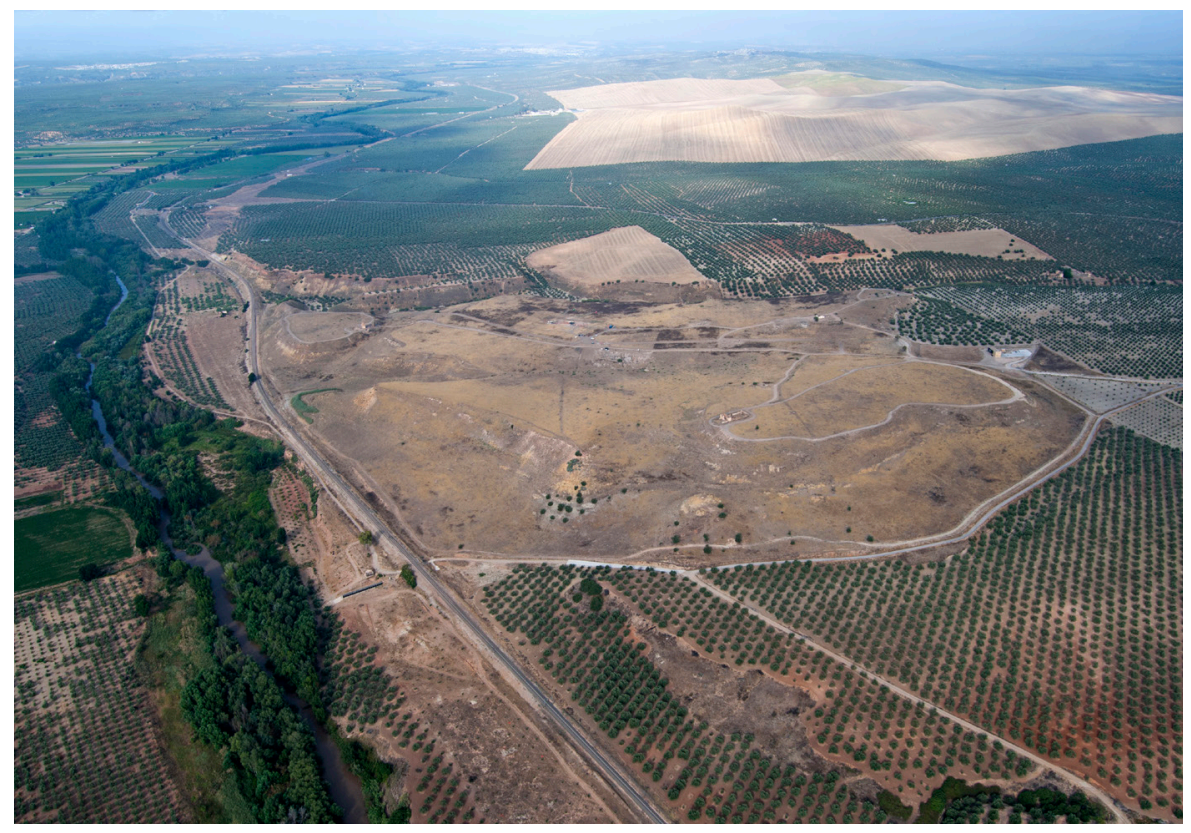

Yacimiento arqueológico de Cástulo (Linares) | foto Proyecto Forum MMX (Marcelo Castro)

Debe destacarse el interés cultural que los restos arqueológicos de Cástulo han suscitado a lo largo de los siglos. Poco tiempo después del definitivo despoblamiento de la ciudad en el siglo XV, su emplazamiento fue visitado por humanistas como Ambrosio de Morales, Francisco de Rus Puerta, Martín de Ximena Jurado, Gregorio López Pinto, que inician una tradición de estudio y recuperación de los restos arqueológicos mantenida durante el siglo $X X$ con los trabajos liderados por José María Blázquez (BLÁZQUEZ; GARCÍA-GELABERT, 1994). Ya en el siglo XXI, y a partir del año 2011, la actividad en la zona arqueológica se reactivó con los proyectos Forum MMX y Siglo XXI en Cástulo, dirigidos ambos por Marcelo Castro (CASTRO, 2015).

La zona arqueológica de Cástulo comprende una porción del territorio de la provincia de Jaén articulada por el río Guadalimar, que la surca en dirección noreste-suroeste, unos kilómetros antes de su encuentro con el río Guadalquivir en el paraje de Iznadiel. El cauce se percibe como un corredor, donde aún se conserva un bosque-galería de extraordinario valor ecológico, que conecta aguas arriba la campiña donde se encuentra Cástulo con la sierra, y aguas abajo, obviamente con el Guadalquivir, que en unos pocos kilómetros también recibirá el caudal del Guadalbullón desde su margen izquierda, y del Guadiel y el Rumblar desde la derecha.

La ciudad se encuentra amurallada, habiéndose documentado la existencia de lienzos de muralla superpuestos pertenecientes a diferentes fases históricas con continuidad desde el siglo VIII a. de C. Destaca la muralla de época 


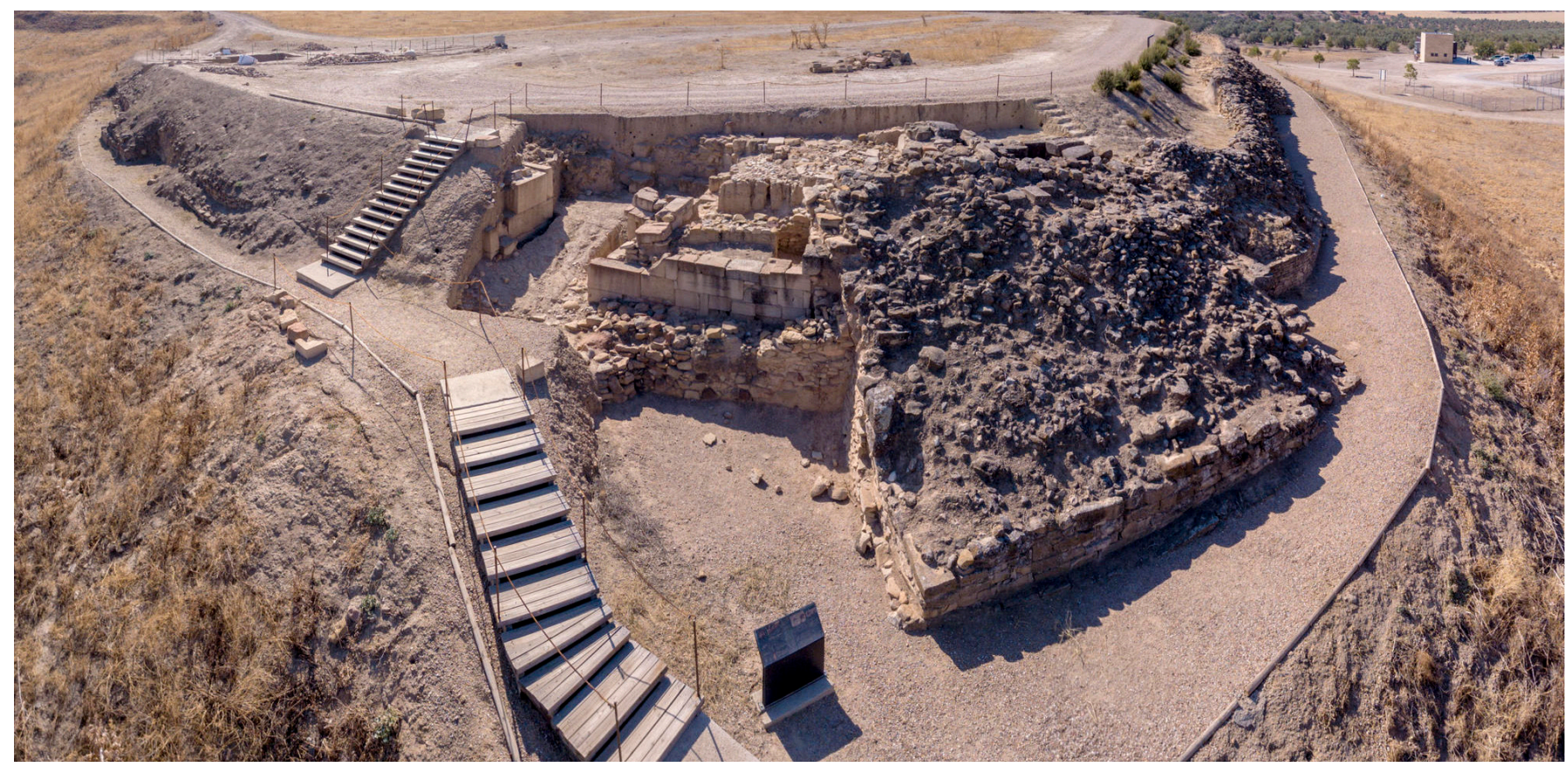

Superposición de lienzos de muralla de diferentes fases históricas junto al área 3 | foto Proyecto Forum MMX (Marcelo Castro)

ibérica asociada a una gran torre y algunas estructuras que fueron destruidas hacia el siglo III a. de C., en el contexto de la II Guerra Púnica. De forma inmediata y superpuesta a las anteriores estructuras descritas, se construye una nueva fortificación de grandes sillares perfectamente labrados: la muralla y la puerta republicana de Cástulo. Esta fortificación y la puerta se construyeron entre los siglos II y I a. de C. (BARBA; FERNÁNDEZ; JIMÉNEZ, 2015).

La ciudad ibero-romana de Cástulo, emplazada en la margen derecha del río Guadalimar, constituyó uno de los centros capitales del mediodía peninsular durante la Antigüedad, tanto por la extensión de su recinto amurallado (50 ha), como por su posición estratégica en la cabecera del valle del Guadalquivir. La ciudad de Cástulo tiene una secuencia histórica de más de cuatro mil años que comprende desde la Prehistoria hasta el final de la Edad Media, un núcleo de población en el que han convivido numerosas culturas autóctonas con otras procedentes del ámbito mediterráneo. Las prospecciones arqueológicas realizadas sobre las terrazas del río Guadalimar y el entorno de Cástulo han permitido documentar la presencia de materiales líticos del Paleolítico Medio adscritos a neanderthales (180.000 a. de C.-40.000 a. de C.). No obstante lo anterior, el origen de la ocupación de este lugar parece indicarlo un silo de forma acampanada que contenía materiales de la Edad del Cobre excavado en parte en la base geológica y seccionado a su vez por la excavación de la fosa de fundación del torreón de Santa Eufemia (CASTRO, 2015). 
Los primeros asentamientos estables documentados en Cástulo están fechados en torno al siglo VIII a. de C. Uno de los más conocidos es el poblado de la Muela. Este poblado se extiende por la ladera este y sudeste de la meseta, desde el cerro de la Muela hasta el río Guadalimar. En este lugar se pudo excavar parte de una edificación identificada como un templo-palacio. Por los elementos recogidos en las excavaciones, entre los que destacan ánforas de tipo fenicio y los primeros productos realizados a torno, así como cerámicas pintadas tipo Carambolo, puede determinarse que en este momento hay una fuerte vinculación de Cástulo con el mundo tartésico del Bajo Guadalquivir.

En época ibérica se produjo un importante desarrollo gracias a incorporación de nuevas tecnologías y a las transformaciones sociales provocadas por la influencia de griegos y fenicios. En estos momentos el oppidum de Cástulo se convirtió en la ciudad más extensa de la Península Ibérica, hasta el punto de acuñar su propia moneda usando la esfinge como su símbolo. Las necrópolis situadas en el entorno de Cástulo se convierten en una herramienta muy útil para seguir el desarrollo de la ciudad a lo largo de su historia. En los siglos VII y VI a. de C. empieza a surgir en Cástulo una aristocracia local, cuyos personajes más influyentes se van a enterrar en grandes recintos funerarios y con un importante ajuar como son el túmulo $A$ de los Higuerones, la sepultura de Casablanca, la sepultura de la finca Torrubia o la sepultura 1 de Baños de la Muela, frente a otros que se entierran con una simple urna resguardada a veces por piedras de pequeño tamaño (necrópolis de los Patos).

En los siglos siguientes se consolida este poder desarrollándose plenamente la cultura ibérica y convirtiéndose Cástulo en el oppidum principal, núcleo fundamental de población de la Oretania. El desarrollo demográfico de Cástulo en el siglo IV a. de C. queda demostrado por el hecho de que, a finales del siglo $\mathrm{V}$ a. de $\mathrm{C}$. y hasta mediados del s. IV a. de C., están en funcionamiento en los alrededores de la ciudad al menos cinco necrópolis a la vez: Molino de Caldona, los Patos, Baños de la Muela, Estacar de Robarinas y los Higuerones. En la mitad del siglo IV a. de C. se dejan de usar las áreas sepulcrales antes mencionadas y no aparecen nuevas necrópolis hasta el siglo II a. de C. Existen por lo tanto dos periodos bien diferenciados, uno con las necrópolis anteriores a la mitad del siglo IV a. de C., y otro con las necrópolis posteriores a esta fecha: Puerta Norte, Cerrillo de los Gordos y Estacar de Luciano, tres necrópolis ibero-romanas que marcan un paso importante en la historia de Cástulo, el paso de una sociedad ibera a una ya completamente romana.

A finales del siglo III a. de C. la ciudad se vio envuelta en los acontecimientos históricos ocurridos en el contexto de la II Guerra Púnica, como consecuencia del interés de romanos y cartagineses por dominar una de las regiones 
más ricas en cuanto a recursos materiales y humanos. En el año 206 a. de C. Roma conquista definitivamente Cástulo con el general Publio Cornelio Escipión. Desde entonces la ciudad formará parte de este Imperio hasta la caída del mismo con la crisis iniciada en el siglo III d. de C.

La ciudad romana, a pesar de los expolios y lagunas de investigación que limitan su conocimiento, alcanzó un destacado esplendor y relevancia a finales del siglo I d. de C. Una ciudad con un teatro adornado con estatuas, termas, letrinas, acueducto, foro y en la que se habrían celebrado espectáculos de gladiadores en un anfiteatro. Cástulo cuenta además con una red de abastecimiento que incluye acueductos, canalizaciones, depósitos y fuentes (CHOCLÁN, 2012; CASTRO, 2015).

La ciudad resurge de sus cenizas en los siglos IV y V, cuando se convierte en sede episcopal y se construye, sobre las termas romanas, una habitación rectangular de grandes dimensiones con cabecera absidal al este y ubicada en el centro geográfico de la ciudad. El obispo, que necesitaba un lugar para construir su nuevo complejo episcopal, debió pensar que las antiguas termas era el mejor edificio donde construir un templo para simbolizar la supremacía y la victoria del cristianismo y de su poder. Esta forma de actuar era algo muy común, puesto que la existencia de templos cultuales cristianos sobre antiguas termas paganas es un hecho que se constata en muchos lugares tanto de la Península Ibérica como en otras regiones extra-peninsulares (JIMÉNEZ; SALES, 2004).

Las fases finales de ocupación de Cástulo la marcan la presencia islámica, la construcción en su interior del torreón de Santa Eufemia y el avance cristiano que determinó la conquista castellana del sitio a principios del siglo XII. El lugar fue definitivamente abandonado, tras varios intentos de repoblación, a mediados del siglo XV (CHOCLÁN, 2012; CASTRO, 2015)

\section{CÁSTULO: ESTUDIOS ARQUEOMÉTRICOS}

No cabe duda que para el desarrollo de la investigación, conservación y puesta en valor del patrimonio arqueológico, la aplicación de análisis arqueométricos con técnicas de diversas procedencias (química, biología, geología) constituye un valor añadido que no debe dejarse de lado. El creciente desarrollo tecnológico, la mejora de los sistemas de muestreo y el reconocimiento de la arqueología como disciplina interdisciplinar, han incidido aún más en los beneficios de los análisis arqueométricos.

En toda la historia de las investigaciones en Cástulo en los siglos XX y XXI se comprueba que una de las carencias en la investigación de esta zona arqueológica reside en la escasez de análisis arqueométricos de diversos 
materiales característicos de las fases de ocupación del área sometida a estudio (desde el Paleolítico al siglo XV, pasando por el periodo orientalizante, ibérico, romano, visigodo e islámico).

Tan sólo pueden reseñarse, en el marco de las investigaciones dirigidas por José María Blázquez y M. ${ }^{a}$ Paz García-Gelabert, el análisis de pastas en cerámicas iberas y romanas empleando difracción de rayos $X$ (LINARES; BARAHONA, 1979; RINCÓN, 1985), el estudio de la decoración roja y negra de fragmentos cerámicos orientalizantes del templo de la Muela empleando difracción de rayos $X$, microscopía electrónica de barrido y espectrometría de absorción atómica (RINCÓN, 1981a; 1981b), y algunos análisis de escorias y elementos metálicos utilizando igualmente difracción de rayos $X$ (LAMELA, 1985; MADROÑERO DE LA CAL; ÁGREDA, 1988). Más recientemente, en el marco modernizador del proyecto Forum MMX, se ejecutaron dos estudios puntuales realizando análisis físico-químicos. El primero sobre la fabricación y la pintura de uno de los muros de la habitación del famoso mosaico de los Amores (LÓPEZ; LÓPEZ; GARCÍA et ál., 2016) empleando microscopía electrónica de barrido con detector de energía dispersiva (SEMEDX) y difracción de rayos $X(X R D)$. El segundo fue un estudio realizado por el Instituto de Restauración del Patrimonio de la Universidad Politécnica de Valencia sobre 12 muestras, también con pintura de diversos colores (azul, rojo, negro), de los muros de varias habitaciones de época romana (DOMÉNECH, 2012). En este caso se emplearon la SEM-EDX y espectroscopía infrarroja con transformada de Fourier (FT-IR).

Si la situación en el ámbito de los análisis físico-químicos refleja una evidente insuficiencia de datos, en el campo de los análisis arqueobotánicos nunca se habían puesto en práctica estrategias para la investigación de restos de semillas y carbones. Fue a partir del año 2011 cuando se empezó a incluir en el proceso de investigación de Cástulo un muestreo sistemático de recuperación de muestras de tierra de diferentes fases y estructuras arqueológicas para una posterior flotación y ejecución de análisis carpológicos y antracológicos.

\section{CÁSTULO: EL NUEVO PROYECTO}

\section{Objetivos}

El proyecto Cástulo: investigación arqueométrica y transferencia social pertenece al Programa Estatal de I+D+i orientado a los "Retos de la Sociedad", del Ministerio de Economía, Industria y Competitividad (HAR2016-74917-R) y tiene una duración de tres años y medio (de diciembre de 2016 a julio de 2020). Está dirigido desde el Instituto Universitario de Investigación en Arqueología Ibérica de la Universidad de Jaén (IUIAI), y en él participan el 
Conjunto Arqueológico de Cástulo, el Departamento de Química Física y Analítica de la Universidad de Jaén y los Departamentos de Arqueología y Química Analítica de la Universidad de Gante (Bélgica).

El punto de partida del proyecto defiende la entidad conjunto arqueológico, en este caso ejemplificada en el caso de Cástulo, como marco adecuado y deseable para compatibilizar investigación y trasferencia social. La vertiente social de la investigación, el contacto con la ciudadanía, tiene un marco de visualización ejemplar en entornos patrimoniales como el Conjunto Arqueológico de Cástulo. El decreto de creación de este conjunto establece claramente cuáles son sus funciones: "custodia, administración, protección, conservación, investigación y difusión de la zona arqueológica de Cástulo y del Museo Monográfico de Cástulo, en el que se llevará a cabo la musealización de la secuencia de ocupación de su territorio a lo largo de la historia por medio de la exposición de la colección arqueológica recuperada en las excavaciones o vinculada a la zona arqueológica" (art 2.1. DECRETO 261/2011, de 26 de julio). El proyecto presenta una serie de objetivos fundamentales que permiten mantener la anterior propuesta:

> Investigar las fases más interesantes del sitio Conjunto Arqueológico de Cástulo y qué más materiales han generado (siglo VII a. de C. al siglo V d. de C., periodos orientalizante, ibérico y romano) mediante su análisis arqueométrico, que hasta el momento habían recibido poca atención pero que almacenan un gran potencial informativo. Se aplican análisis físico-químicos sobre cerámicas, recubrimientos pintados, pavimentos y mosaicos, y se llevan también a cabo análisis arqueobotánicos de tipo antracológico y carpológico.

> Transformar en información accesible el resultado de la investigación arqueométrica e interdisciplinar que combina las áreas de las ciencias experimentales (química y biología) con las humanísticas. Realizada la transformación, se podrá completar el discurso interpretativo sobre el pasado en sus diferentes vertientes.

$>$ Generar conocimiento sobre los materiales analizados para diseñar las mejores estrategias de conservación y restauración empleando técnicas de análisis no destructivas.

> Diseñar y mejorar los canales de trasmisión y transferencia del nuevo conocimiento. Paralelamente al campo de la investigación especializada, el proyecto busca desarrollar el potencial del conjunto como marco de desarrollo económico y profundizar en la apropiación social del patrimonio arqueológico entendida como el motor imprescindible para que siga siendo investigado y conservado en el futuro. Los eventuales beneficios del proyecto en este campo deben repercutir principalmente en la ciudadanía. 
El proyecto se adecúa además a las líneas principales de la Estrategia Española de Ciencia y Tecnología y de Innovación en cuanto que se integra en el reto 6 denominado "Cambios e innovaciones Sociales" y se ajusta a lo establecido en el programa Ciencia para y con la Sociedad del Programa Horizonte 2020 de la Unión Europea.

\section{Área y materiales analizados}

Para llevar a cabo estos objetivos se han delimitado las zonas y materiales susceptibles de ser analizados. El ámbito de actuación del proyecto se centra en los materiales cerámicos decorados procedentes de las necrópolis situadas en el entorno de Cástulo depositadas en el Museo de Cástulo, y en los materiales procedentes de las excavaciones llevadas a cabo en el poblado entre 2011 y 2016 (ver tabla de p. 54).

En este segundo caso, las zonas más interesantes desde el punto de vista arqueométrico serían el área 2 (edificio D romano), área 3 (estructuras de habitación orientalizantes e ibéricas) y el área 4 (santuario púnico de la Torre Alba). De estas zonas se han seleccionado estucos decorados con pinturas, mosaicos y recipientes cerámicos. También de estas excavaciones proceden todas las muestras carpológicas y antracológicas recuperadas manualmente o a través de la flotación de los sedimentos que se extrajeron durante las intervenciones arqueológicas.
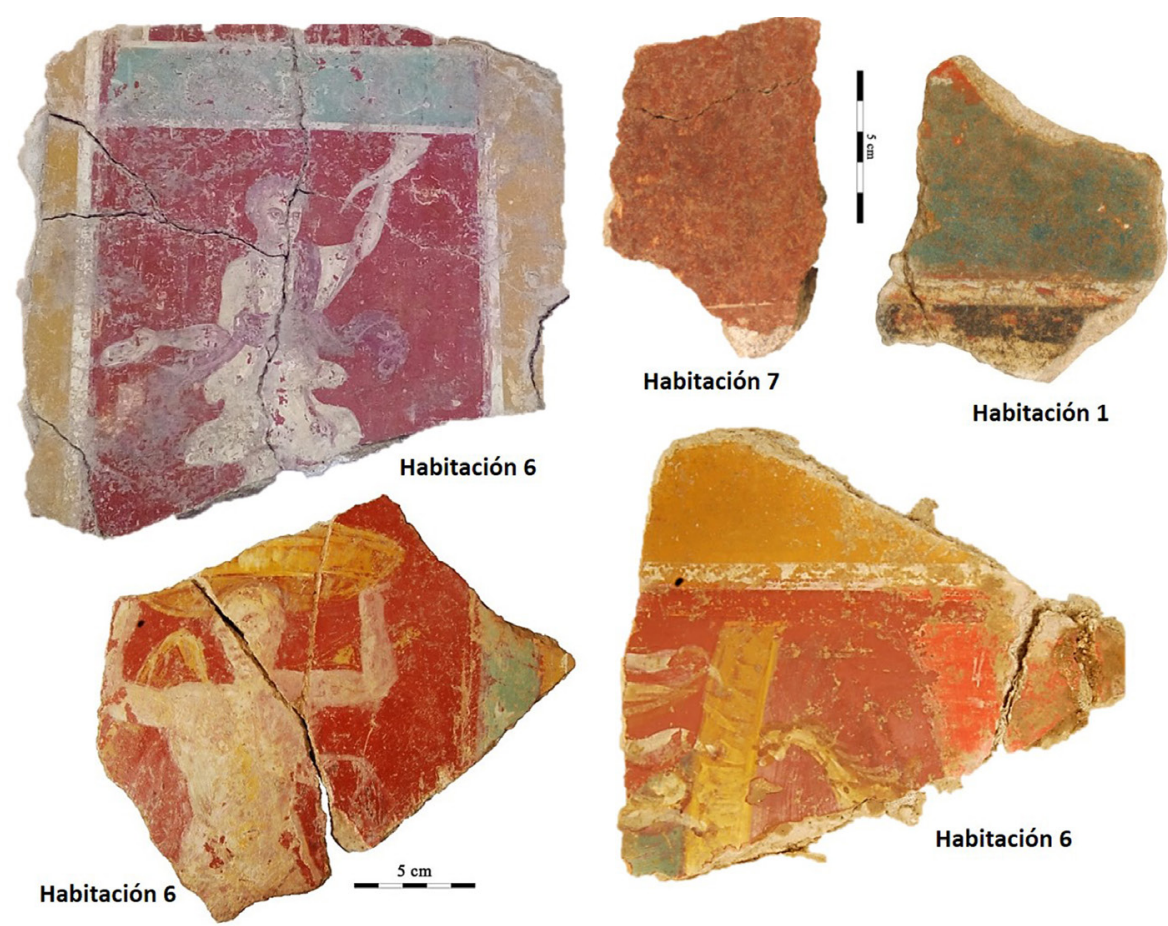


\begin{tabular}{llll}
\hline ÁREA & ESTRUCTURA & MATERIAL SELECCIONADO & CRONOLOGÍA \\
\hline 1 & Estructuras de habitación & Semillas, carbón, cerámicas & IV-V d. de C. \\
\hline 2 & Edificio D & Mosaico, cerámicas, estucos decorados, semillas, carbón & I-II d. de C. \\
\hline 3 & Estructuras de habitación & Semillas, carbón, cerámicas & VII-III a. de C. \\
\hline 4 & Santuario Torre Alba & Semillas, carbón, cerámicas & II a. de C.- I d. de C. \\
\hline Museo & Necrópolis & Cerámicas & VII a. de C.-IV d. de C.
\end{tabular}

Procedencia, tipos de material y cronología

Área central del mosaico de los Amores (estancia 1, edificio D, área 2) | foto Proyecto Forum MMX (Marcelo Castro)

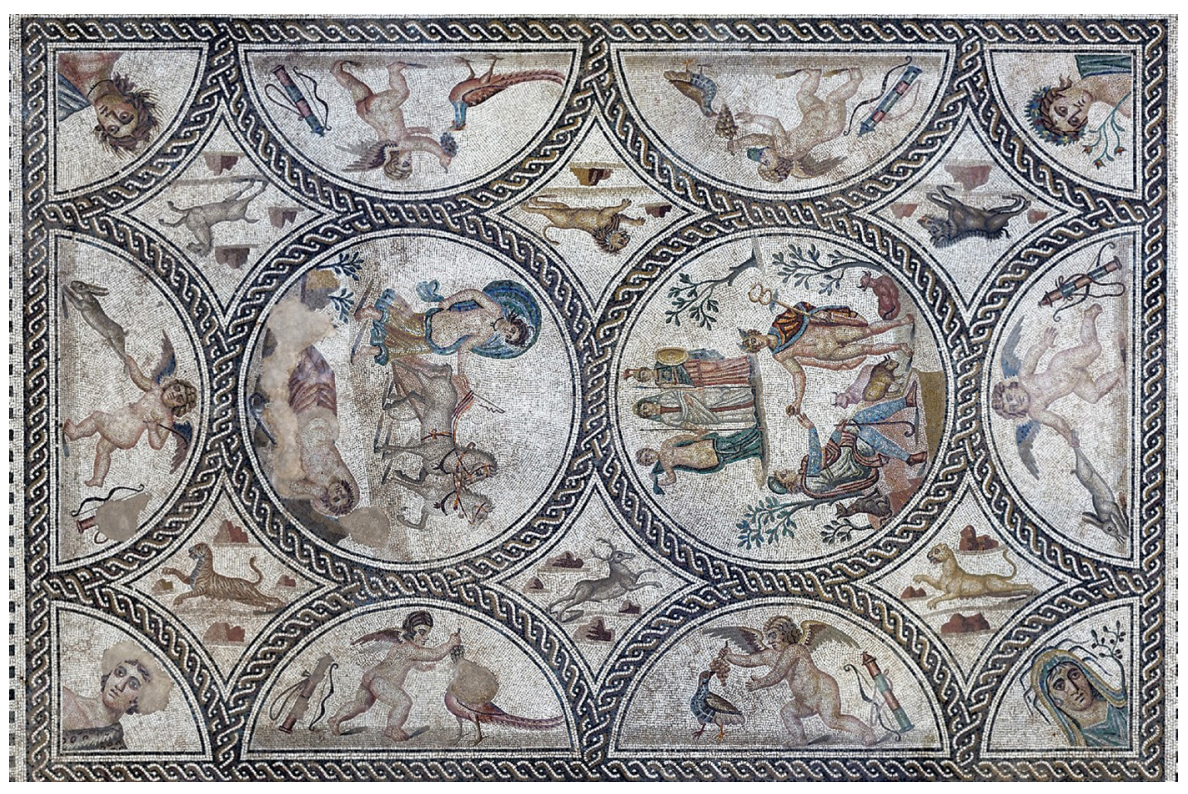

De especial importancia es el edificio D, de finales del siglo I d. de C., y construido para rendir culto al emperador Domiciano y en el que se expondría un programa de legitimación de su poder. Como parte de ese programa habría que entender el famoso mosaico de los Amores en los que un diseño iconográfico centrado en las escenas Selene y Endimión y el Juicio de Paris desarrolla esa idea legitimadora. Otras habitaciones del edificio muestran otros mosaicos pero con diseños geométricos no figurados. También en este edificio destacan la presencia de pinturas decorando los estucos presentes en las paredes (JIMÉNEZ, 2014). Este edificio ha sido hasta el momento uno de los principales focos de actuación del proyecto.

\section{Análisis físico-químicos}

Este análisis parte de una consulta previa a las fuentes escritas clásicas, especialmente Vitrubio y Plinio, sobre los materiales empleados por los romanos en la construcción y decoración de edificios. Los análisis físico-quí- 
micos aportan información sobre los procesos de trabajo y las materias primas empleadas en la elaboración de las decoraciones cerámicas y pinturas murales y en las teselas de los mosaicos. Por su parte, el análisis de contenidos es de vital importancia a la hora de reconocer los productos consumidos y su participación en otras actividades ajenas al consumo como pueden ser acciones de tipo ritual o religioso. La metodología empleada permite también la identificación de sustancias aglutinantes o protectoras en las pinturas murales y que tanto debate suelen suscitar (ABAD, 1982; CUNí; CUNí; EISEN et ál., 2012) (ver tabla de abajo).

Para el estudio de las materias primas empleadas en la decoración de la cerámica y en la fabricación de mosaicos y pinturas murales se han elegido como técnicas de aplicación prioritaria la micro-espectroscopía Raman (MRS), para los análisis mineralógicos, y la fluorescencia de rayos $X$ de energía dispersiva (EDXRF), para los análisis elementales. En ambos casos se utiliza equipamiento de laboratorio y portátil (TUÑÓN; SÁNCHEZ; PARRAS et ál., 2016; VANDENABEELE; DONAIS, 2016). Ambas son técnicas no destructivas, es decir, la preparación de las muestras queda reducida a su limpieza (para eliminar la suciedad que pudieran llevar adherida). Esta circunstancia, además de ser deseable en el caso del estudio de muestras de interés arqueológico, permite que los análisis puedan ser repetidos variando las condiciones experimentales o la región de medida, lo que otorga mayor representatividad a los resultados obtenidos. Con ambas técnicas las muestras pueden visualizarse a diferentes escalas con distintos

\begin{tabular}{|c|c|c|c|}
\hline TÉCNICA & EQUIPO & CARACTERÍSTICAS & MATERIAL \\
\hline \multirow{6}{*}{ MRS } & BWTEK InnoRam & 785 nm, portátil & Pintural mural, mosaico, cerámica \\
\hline & BWTEK iRaman Ex & 1064 nm, portátil & Pintural mural, mosaico \\
\hline & Bruker BRAVO & 700 a 1100 nm, portátil & Mosaico \\
\hline & TSI Inc.EZ-Raman-I Dual (DG) & 785nm/532 nm, portátil & Mosaico \\
\hline & Renishaw InVia Reflex & $785 \mathrm{~nm} / 514,5 \mathrm{~nm}$ & Pintural mural, mosaico, cerámica \\
\hline & Renishaw Qontor & $480 \mathrm{~nm} / 532 \mathrm{~nm} / 785 \mathrm{~nm}$ & Pintural mural, mosaicos \\
\hline \multirow{3}{*}{ EDXRF } & Bruker M4 Tornado & Rh (50kV) & Pintural mural, mosaico, cerámica \\
\hline & Bruker Tracer III SD & Rh (40kV) portátil & Mosaico \\
\hline & Olympus InnovX Delta & Rh (40kV) portátil & Mosaico \\
\hline GC-MS & $\begin{array}{l}\text { ThermoFisher CromatógrafoTraceGC } \\
\text { Espectrómetro MasasThermoDC Q II }\end{array}$ & $\begin{array}{l}\text { Ionización electronica } 5 \text { m x0.25 mm, } \\
0.1 \mu \mathrm{m} \text { i.d. } \\
\text { Derivados TMS }\end{array}$ & Pintural mural, cerámica \\
\hline HPLC-MS & $\begin{array}{l}\text { Agilent } 1290 \text { Infinity HPLC system } \\
\text { Espectrómetro Masas } 6220 \text { TOF }\end{array}$ & $\begin{array}{l}\text { Fuente } \mathrm{APCl} \\
\mathrm{C} 18,4.6 \times 150 \mathrm{~mm} \\
\text { Triglicéridos }\end{array}$ & Pintural mural, cerámica \\
\hline
\end{tabular}




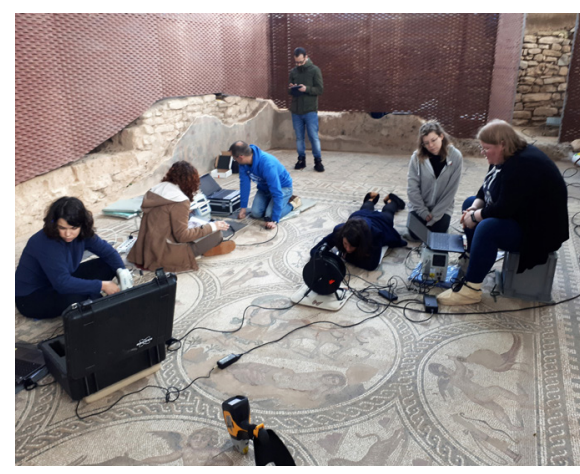

sistemas de enfoque, pudiéndose identificar así la sucesión de estratos o capas decorativas.

Para el análisis de indicadores orgánicos de contenidos (lípidos y ceras) en recipientes cerámicos y en las pinturas murales las técnicas utilizadas son la cromatografía de gases-espectrometría de masas (GC-MS) y cromatografía líquida de alta resolución-espectrometría de masas (HPLC-MS). Con GC-MS se obtiene un perfil lipídico general que permite la identificación de ácidos grasos, esteroles, acilgliceroles y ceras de abeja. El uso de HPLC-MS, por su alta sensibilidad, permite obtener un perfil de triacilgliceroles más preciso y diferenciar entre grasas procedentes de animales rumiantes y no rumiantes (PARRAS; SÁNCHEZ; TUÑóN et ál., 2015).

Dada la gran cantidad de datos físico-químicos acumulados, no se tendrán resultados hasta finales del año 2020; sin embargo, los obtenidos hasta el momento son muy prometedores. Este sería el caso de las pinturas con las que se decoraban los estucos romanos. A partir del análisis por MRS y EDXRF se han identificado, en un conjunto de 11 fragmentos de las habitaciones 1,6 y 7 del edificio $D$ (segunda mitad del siglo I d. de C.), un repertorio básico de materias primas empleadas en la elaboración de los colores: rojo (hematites, litargirio y cinabrio), amarillo (goethita), verde (tierras verdes), blanco (calcita) y azul (azul egipcio). De especial interés es la aparición de cinabrio en la habitación 6 del edificio D, mineral cuyo uso habrían descartado investigaciones anteriores y cuya presencia, por su carácter exclusivo, es coherente con lo excepcional del edificio en el que se encontró.

También, en relación con el análisis de las paredes decoradas del edificio D, se ha llevado a cabo el análisis por GC-MS y HPLC-MS de componentes orgánicos empleados en la elaboración de los pigmentos. En un fragmento decorado de la pared del espacio 1, correspondiente al Mosaico de los Amores, se ha identificado la presencia de cera de abeja y grasa de origen animal. Este hecho, que debe confirmarse con un mayor número de fragmentos analizados, estaría indicando que en la elaboración de las pin-

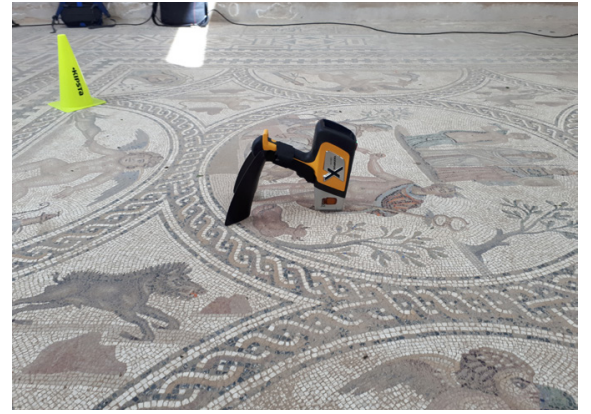

Análisis in situ de la estancia 1 (edificio D, área 2) con equipamiento portátil MRS y EDXRF | fotos Alberto Sánchez turas que decoraban las paredes de esta habitación se usaba la técnica encáustica. Por su parte, en la habitación 6 , contigua a la anterior, el análisis empleando la misma metodología indicó el uso de grasa vegetal muy insaturada (alta presencia de ácido linoleico) destinada muy probablemente a cumplir la función de aceite secante.

En referencia a los análisis in situ realizados por MRS y EDXRF sobre 600 teselas del mosaico de los Amores, los primeros resultados permiten clasificarlas en dos grupos: teselas de piedra y de pasta vítrea. Entre las primeras se han diferenciado las fabricadas con roca caliza, dolomía y hematites para teselas de color negro, blanco, gris, rosáceo y rojo. Entre las fabricadas en pasta vítrea se han identificado hasta el momento agentes cromóforos, como 
son el cobre para las de color verde y el cobalto para las azules, y el antimoniato de calcio como agente que confiere opacidad a las teselas vítreas.

El análisis de contenidos por GC-MS en recipientes cerámicos ha permitido detectar la presencia de azufre nativo en dos recipientes iberos del siglo IV a. de C. (un recipiente globular y un cuenco) recuperados del área 3. Este compuesto debe ser asociado con procesos de purificación relacionados con el desarrollo de rituales y con la limpieza de objetos (PARRAS; SÁNCHEZ; TUÑóN et ál., 2015).

\section{Análisis arqueobotánicos: análisis antracológico y carpológico}

Estos análisis resultan fundamentales para obtener el marco paleoambiental del entorno del sitio arqueológico necesario para explicar la evolución y cambio en la sociedad de Cástulo a lo largo de los siglos. Asimismo, y en relación con lo anterior, deben aclarar la estrategia de explotación económica del entorno de Cástulo, prestando atención al desarrollo de la agricultura en el Alto Guadalquivir durante la época ibero-romana, haciendo especial mención a la arboricultura.

Desde el inicio de las campañas de excavación en el 2011, además de la recuperación de semillas y carbones de forma manual, se aplicó un muestreo sistemático para la recogida de sedimentos en los diversos espacios y fases excavadas (siglos VIII a. de C. al siglo IV d. de C.) con la intención de recuperar restos vegetales y otros ecofactos para su posterior estudio. Una vez realizada la flotación de los sedimentos disponibles, 4.443 litros de sedimento correspondientes a las campañas de 2011 hasta 2015, se han identificado un total de 4.144 restos carpológicos y 3.234 restos de carbón.

\section{Análisis antracológico}

La utilización de leña para los fuegos y de madera para la construcción de cabañas, útiles y herramientas fue constante y cotidiana para las sociedades prehistóricas y, también, preindustriales. La principal fuente de energía se obtenía de la leña, bien utilizada directamente en los fuegos o haciendo carbón vegetal. Los restos carbonizados de las especies utilizadas para tal fin son los que estudia la antracología, junto con los restos constructivos o de utensilios que se quemaron en los fuegos fortuitos o intencionados que se produjeron en los poblados. Estos restos no sólo aportan información paleoambiental sino también informan de la gestión que del medio vegetal realizan las distintas comunidades humanas.

Para la visualización de los carbones se ha utilizado un microscopio de luz reflejada (Olympus BX50) del Laboratorio de Paleoambiente del IUIAI y para la realización de las fotos el microscopio electrónico de barrido (SEM) de los Servicios Técnicos de Investigación de la Universidad de Jaén. La identifi-
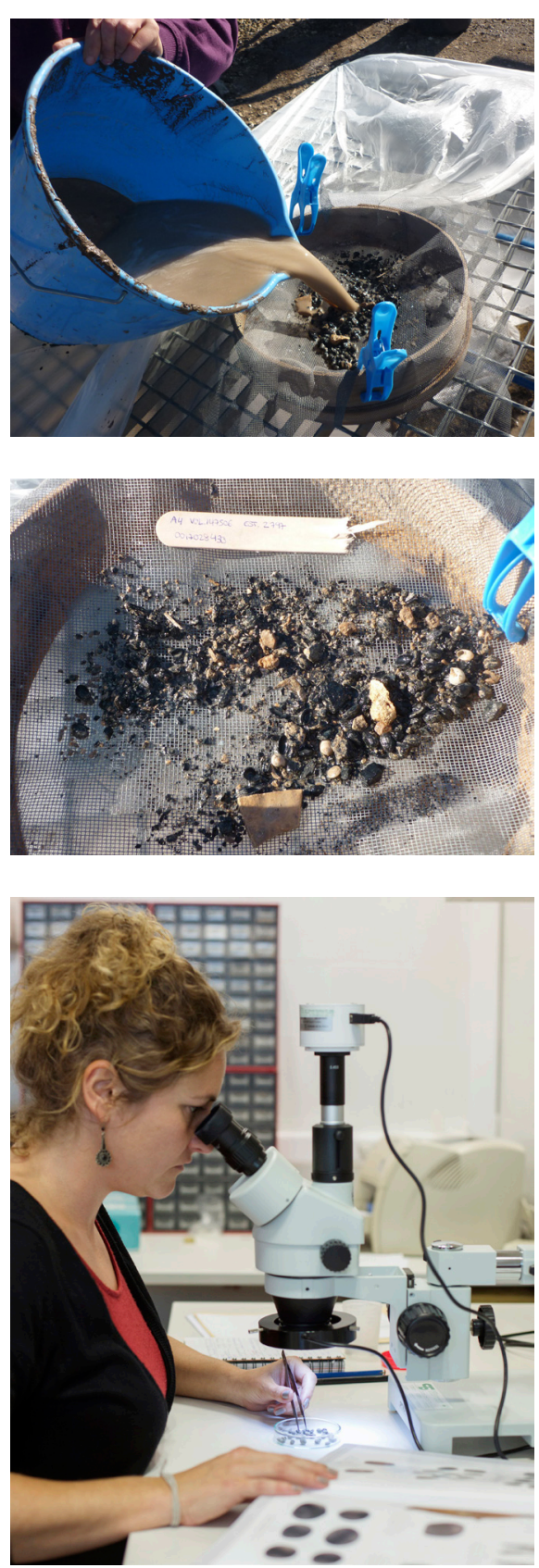

Detalle del proceso de flotación de sedimento arqueológico y el posterior estudio carpológico | fotos Eva Montes 

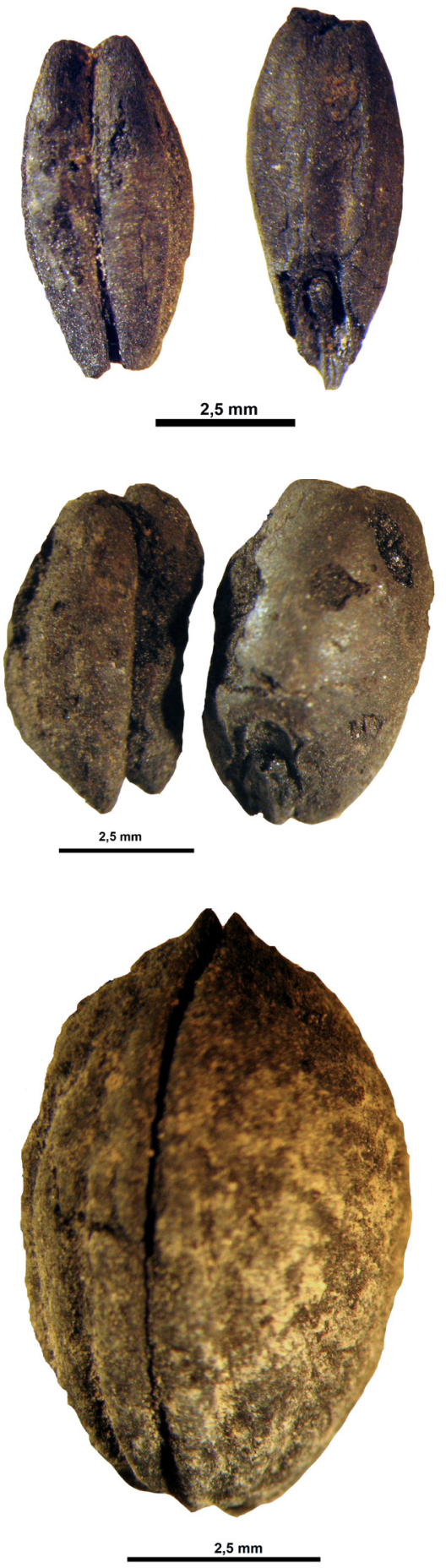

Selección de semillas identificadas: a) Hordeum vulgare (cebada), b) Triticum aestivum (trigo), c) Olea europaea (aceituna) | fotos Eva Montes cación antracológica de los taxones se ha realizado mediante la comparación de la anatomía del xilema secundario con varios atlas de anatomía de la madera (VERNET; OGEREAU; FIGUEIRAL et ál., 2001) y con la colección de referencia de maderas actuales carbonizadas del IUIAI. En el estudio antracológico se ha utilizado el recuento de los fragmentos de carbón como la base del estudio cuantitativo, a partir del cual se han de inferir los datos paleoecológicos. La interpretación antracológica se ha realizado en base al espectro florístico o lista de taxones determinados.

\section{Análisis carpológico}

La carpología es una disciplina especializada en el estudio de semillas y frutos. Su objetivo es el conocimiento de las especies vegetales que conviven dentro del asentamiento y su entorno inmediato -por ejemplo, los campos de cultivo-, así como la manipulación de los alimentos y su consumo. Con este tipo de análisis se pueden diferenciar especies silvestres y cultivadas, conocer las prácticas agrícolas y obtener información del medio vegetal que rodeaba el asentamiento así como los pilares sobre los que se asentaba la economía de los primeros grupos humanos.

Las semillas se han visualizado con la lupa Leica MZ6 del Laboratorio de Paleoambiente del IUIAI y a la que se le ha adaptado una cámara digital Canon S80 para la realización de fotos. La identificación de semillas y frutos se realiza teniendo en cuenta la morfología externa, la biometría y la comparación de la anatomía de los ejemplares arqueológicos con semillas y frutos actuales. Para ello, se han utilizado las colecciones de referencia actual del IUIAI y diferentes atlas de determinación y trabajos especializados (BUXÓ, 1997; RODRÍGUEZARIZA; MONTES, 2005; PEÑA-CHOCARRO; PÉREZ; ALONSO et ál., 2019). La identificación taxonómica de las semillas y los frutos sigue la sistemática de Flora europaea (TUTIN; HEYWOOD; BURGES et ál., 1964-1980).

Los primeros datos obtenidos a partir de la integración de la información procedente de los restos de semillas y carbones son bastante prometedores. Estarían indicando una primera fase de época ibérica en la que el paisaje de encinar sería dominante, acompañado por un importante desarrollo del cultivo de cereal y, en menor medida, por presencia de almendros. Ya en época romana, y sobre todo en el cambio de era, se documenta un descenso en la presencia de encinares con una transformación de la vegetación del entorno de Cástulo al introducirse de manera muy significativa el cultivo del olivo como consecuencia de un cambio económico y de ordenación del territorio en época romana.

\section{Difusión e integración social}

El Conjunto Arqueológico de Cástulo es el marco ideal, por su cercanía y contacto con el tejido social, para transmitir y hacer accesible la información 
procedente de la actividad investigadora. El artículo 8 del decreto de creación del conjunto establece la existencia de un Área de Difusión que "tendrá por finalidad el acercamiento del Conjunto Arqueológico a la sociedad, mediante la aplicación de métodos didácticos y técnicas de comunicación y la organización de actividades complementarias que faciliten la comprensión y el disfrute de los bienes culturales de la institución" (DECRETO 261/2011). En relación con esta obligación, los avances y conclusiones históricas y arqueométricas que el proyecto han generado están integradas en un programa de difusión que se articula en una doble vertiente especializada y generalizada.

La difusión especializada está dirigida al sector académico y científico por lo que requiere de la realización de publicaciones en revistas especializadas de ámbito nacional e internacional. De forma paralela se pretende compartir esta información a través de la participación en congresos de carácter nacional e internacional, simposios, seminarios y conferencias que estén relacionados con las mismas áreas temáticas. En este momento ya se han realizado presentaciones del proyecto en los siguientes congresos internacionales: XIII GeoRaman Conference (Catania, Italia, junio de 2018), Meeting European Materials Research Society (Estrasburgo, Francia, junio de 2018), X Iberian Spectroscopy Conference y XXVI National Spectroscopy Meeting (Lisboa, Portugal, julio 2018) y VII Technart (Brujas, Bélgica, mayo de 2019).

La difusión generalizada, dirigida al público en general, cuenta con diversas posibilidades y entornos para hacer efectiva la transferencia. El Conjunto Arqueológico de Cástulo (museo y oppidum) representa el marco ideal para transmitir con inmediatez los nuevos datos surgidos del proyecto. El Conjunto, desde 2011 y en el marco del proyecto Forum MMX, ha experimentado una subida espectacular en el número de visitas (de 17.640 en 2011 a 57.006 en 2014), por lo que el alcance y repercusión social de la investigación se multiplica.

El proyecto ha colaborado en la exposición Sólo Cenizas. Cuatro tumbas perdidas. Necrópolis Higuerones-Casablanca, realizada en el Museo de Linares del 30 de octubre al 12 de diciembre de 2018. Esta exposición no solo mostraba los ajuares de estas tumbas romanas del siglo I d. de C. localizadas en el entorno de Cástulo, sino también la metodología de trabajo en la que se incluyó el análisis de los recipientes cerámicos y de los carbones y semillas identificados (encinas, quejigo y restos de cáscara de nuez) en los sedimentos del interior de las tumbas.

Dentro también de las actividades de difusión del conjunto arqueológico se ha previsto la realización en mayo de 2020 de unas jornadas de difusión relacionadas con los resultados del proyecto. Se pretende no sólo transmitir los avances históricos, valores identitarios y el respeto por el patrimonio arqueo- 
lógico, sino también aspectos metodológicos que acerquen a la ciudadanía las nuevas tendencias de la investigación científica.

Dirigidos también a la ciudadanía, pero en este caso a los jóvenes, los avances del trabajo de investigación y sus resultados se han transmitido a través de diversos programas de difusión y promoción coordinados por la Universidad de Jaén. Durante la Semana de la Ciencia, celebrada en los años 2017, 2018 y 2019, se mostraron a grupos de estudiantes de 14 años los laboratorios del IUIAI y algunos de los resultados obtenidos por el proyecto sobre los mosaicos y las pinturas murales, así como los tipos de análisis arqueométricos llevados a cabo.

El programa Encuentros 2018, organizado por la Universidad de Jaén para la promoción de los diversos grados impartidos en la Universidad entre los diversos institutos de educación secundaria de la provincia de Jaén, ha sido un marco ideal para la difusión del proyecto. Un total de 45 institutos (450 alumnos) visitaron el IUIAI y recibieron información sobre la arqueología, Cástulo y los análisis que se estaban realizando.

En el marco del Campus científico de verano 2019 (FECYT), se desarrolló un curso titulado Investigar el pasado: arqueología en acción, dentro del cual se organizó un taller de análisis físico-químicos aplicados a la arqueología. En esta actividad se mostraron a 35 alumnos procedentes de diversas provincias de España la metodología de trabajo y la importancia de los análisis físico-químicos para la investigación y puesta en valor del oppidum de Cástulo.

Enfocado a público adulto, el Programa Universitario para Mayores impartió durante los años 2017, 2018 y 2019 el curso La Arqueología de la Cultura Ibérica: desde sus orígenes, y dentro de este se incluyó el tema Arqueometría aplicada al estudio de la Cultura Ibérica. El oppidum de Cástulo y los análisis arqueométricos llevados a cabo en él sirvieron para ilustrar gran parte de citado tema.

La difusión no puede ser ajena a los beneficios de la comunicación on-line. Cástulo, el actual proyecto Siglo XXI en Cástulo y el IUIAI cuentan con páginas web y Facebook como plataformas de difusión de los resultados. Igualmente, los resultados están pasando a formar parte de la base de datos y web de libre acceso Arquiberlab (www.arquiberlab.com) accesible tanto para investigadores como para público en general. En esta web se incorporan las fotos de los objetos, la datación y localización del objeto analizado, los resultados del análisis físico-químicos y la metodología empleada.

Otro de los objetivos de difusión se centra en la transferencia de información a la Biblioteca Digital Europea (Europeana) en formatos digitales 2D y 3D (www.europeana.eu). Europeana es actualmente una de las plataformas 
de difusión del conocimiento que más impulso y apoyo está recibiendo de la Unión Europea. Ya existe información sobre Cástulo en la misma, pero con el trabajo que se está desarrollando y con la participación en el proyecto europeo Europeana Archaeology (Programa CEF-Telecom de la Unión Europea) (www.europeanaarchaeology.carare.eu) se podrá efectuar una actualización con la información procedente de los estudios arqueométricos de tipo físico-químico y paleoambiental. La actualización estará finalizada en julio de 2020.

\section{Agradecimientos}

Los autores agradecen la colaboración y ayuda prestada al Conjunto Arqueológico de Cástulo, Instituto Universitario de Investigación en Arqueología Ibérica y Departamento de Química Física y Analítica de la Universidad de Jaén, al proyecto Arqueología de lo Invisible (HAR2015-73959-JIN), a los Servicios Técnicos de la Universidad de Jaén (CICT), Granada (CIC), Málaga (SCAI), y Sevilla (CITI), al Archaeometry Research Group y Raman Spectroscopy Research Group, ambos de la Universidad de Gante (Bélgica). 


\section{BIBLIOGRAFÍA}

- ABAD, L. (1982) Aspectos técnicos de la pintura mural romana. Lucentum, vol. 1, 1982, pp. 135-171

- BARBA, V.; FERNÁNDEZ, A.; JIMÉNEZ, Y. (2015) La muralla de Cástulo y la Puerta de los Leones. En RUIZ, A.; MOLINOS, M. (ed.) Jaén, tierra ibera 40 años de investigación y transferencia. Jaén: Universidad de Jaén, 2015, pp. 305-321

- BLÁZQUEZ, J. M. (coord.) (1979) Cástulo II. Madrid: Ministerio de Cultura, 1979 (Excavaciones Arqueológicas en España; n. ${ }^{\circ}$ 105)

- BlÁZQueZ, J. M.; GARCíA-GELABERT M. P. (1994) Cástulo, ciudad ibero-romana. Madrid: Ediciones Istmo, 1994

- BLÁZQUEZ, J. M.; VALIENTE, J. (coord.) (1981) Cástulo III. Madrid: Subdirección General de Arqueología, 1981 (Excavaciones Arqueológicas en España; n. ${ }^{\circ}$ 117)

- BLÁZQUEZ, J. M.; GARCÍA-GELABERT, M. P.; LÓPEZ, F. (1985) Cástulo V. Madrid: Ministerio de Cultura, 1985 (Excavaciones Arqueológicas en España; n. ${ }^{\circ} 140$ )

- BUXÓ, R. (1997) Arqueología de las plantas. La explotación económica de las semillas y frutos en el marco mediterráneo de la Península Ibérica. Barcelona: Crítica, 1997

- CAstro, M. (coord.) (2015) Proyecto general de conocimiento siglo XXI en Cástulo. Conjunto Arqueológico de Cástulo (Linares, Jaén). Documento inédito

- CUNÍ, J.; CUNÍ, P.; EISEN, B.; SAVIZKYC, R.; BOVÉ, J. (2012) Characterization of the binding medium used in Roman encaustic paintings on wall and wood. Analytical methods, vol. 4, 2012, pp. 659-669

- CHOCLÁN, C. (2012) Cástulo: radiografía de un territorio. En LEIS, V.; MARTÍNEZ, L.; RABANEDA, L. (coord.) Actas I Congreso de Historia de Linares. Jaén: Centro de Estudios Linarenses, Diputación Provincial de Jaén, 2012, pp. 29-47

- DECRETO 261/2011, de 26 de julio, por el que se crea el Conjunto Arqueológico de Cástulo, en Linares (Jaén). Boletín Oficial de la Junta de Andalucía, n. ${ }^{\circ}$ 155, de 9 de agosto de 2011

- DOMÉNECH, T. (2012) Informe analítico: pinturas murales Cástulo. Instituto de Restauración del Patrimonio de la Universidad Politécnica de Valencia. Informe inédito

- JIMÉNEZ, Y. (2014) El posible edificio de culto imperial. Una reflexión forzosamente penúltima. Siete esquinas, n. ${ }^{\circ}$ 6, 2014, pp. 89-103

- JIMÉNEZ, J. A.; SALES, J. (2004) Termas e iglesias durante la Antigüedad Tardía: ¿reutilización arquitectónica o conflicto religioso? Algunos ejemplos hispanos. Antigüedad y cristianismo: Monografías históricas sobre la Antigüedad
Tardía, vol. 21, 2004, pp. 185-202

- LINARES, F.; BARAHONA E. (1979) Estudio de la cerámica de Cástulo por difracción de rayos $X$. En BLÁZQUEZ MARTÍNEZ (coord.) Cástulo II. Madrid: Ministerio de Cultura, 1979, pp. 255-266 (Excavaciones Arqueológicas en España; n. ${ }^{\circ}$ 105)

- LAMELA, M. (1985) Análisis de minerales y escorias procedentes del poblado de La Muela de Cástulo, LinaresJaén. En BLÁZQUEZ, J. M.; GARCÍA-GELABERT, M. P.; LÓPEZ, F. (coord.) Cástulo V. Madrid: Ministerio de Cultura, 1985, pp. 315-317 (Excavaciones Arqueológicas en España; n. ${ }^{\circ}$ 140)

- LÓPEZ, T.; lÓPEZ, O.; GARCÍA, A.; CALERO, A. I.; MEDINA, V. (2016) Las pinturas murales de Cástulo. Primeras aportaciones a la caracterización de materiales y técnicas de ejecución. Lucentum, vol. XXXV, 2016, pp. 155-170

- MADROÑERO DE LA CAL, A.; ÁGREDA, M. N. I. (1988) Contribución al estudio de la metalurgia de Cástulo. En GARCÍA-GELABERT, M. P.; BLÁZQUEZ, J. M. (ed.) Cástulo, Jaén, España. Excavaciones en la necrópolis ibérica del Estacar de Robarinas (s. IV a. de C.). Oxford: B.A.R. 1988, pp. 343-373 (BAR International Series; 425)

- PARRAS, D. J.; SÁNCHEZ, A.; TUÑÓN, J. A.; RUEDA, C.; RAMOS, N.; GARCÍA-REYES J. F. (2015) Sulphur, fats and beeswax in the Iberian rites of the sanctuary of the oppidum of Puente Tablas (Jaén, Spain). Journal of Archaeological Science: Reports, vol. 4, 2015, pp. 510-524

- PEÑA-CHOCARRO, L.; PÉREZ, G.; ALONSO, N.; ANTOLÍN, F.; TEIRA BRIÓN, A.; TERESO, J. P.; MONTES, E. M.; LÓPEZ, D. (2019) Roman and Medieval crops from the Iberian Peninsula: a first overview of seeds and fruits from archaeological sites. Quaternary International, vol. 499, 2019, pp. 49-66

- RINCÓN, J. M. (1981a) Estudio de la composición de los colorantes superficiales de dos cerámicas del poblado de la Muela de Cástulo (Linares, Jaén). En BLÁZQUEZ, J. M.; VALIENTE, J. (coord.) Cástulo III. Madrid: Ministerio de Cultura, 1981, pp. 237-242 (Excavaciones Arqueológicas en España; n. ${ }^{\circ}$ 117)

- RINCÓN, J. M. (1981b) Estudio comparativo de los colorantes superficiales rojos de varias piezas cerámicas del poblado de La Muela de Cástulo (Linares, Jaén). En BLÁZQUEZ, J. M; VALIENTE, J. (coord.) Cástulo III. Madrid: Ministerio de Cultura, 1981, pp. 243-249 (Excavaciones Arqueológicas en España; n. ${ }^{\circ}$ 117)

- RINCÓN, J. M. (1985) Análisis mineralógico de cerámica común e ibérica de Cástulo. En BLÁZQUEZ, J. M.; GARCÍAGELABERT, M. P.; LÓPEZ, F. (coord.) Cástulo V. Madrid: Ministerio de Cultura, 1985, pp. 331-337 (Excavaciones Arqueológicas en España; n. ${ }^{140)}$ 
- RODRÍGUEZ-ARIZA, M. O.; MONTES, E. (2005) On the origin and domestication of Olea europaea L. (olive) in Andalucía, Spain, based on the biogeographical distribution of its finds. Vegetation, History and Archaeobotany, vol. 14, 2005, pp. 551-561

- TUÑÓN, J. A.; SÁNCHEZ, A.; PARRAS, D. J.; VANDENABEELE, P.; MONTEJO, M. (2016) Micro-Raman spectroscopy on Iberian archaeological material. Journal of Raman Spectroscopy, vol. 47, 2016, pp. 1514-1521

- tUTIN, T. G.; HEYWOOD, V. H.; BURGES, N. A.; VALENTINE, D. H.; WALTERS, S. M.; WEBB, D. A. (19641980) Flora Europaea. Cambridge: Cambridge University Press, 1964-1980

- VANDENABEELE, P.; DONAIS, M. K. (2016) Mobile spectroscopic instrumentation in archaeometry research. Applied Spectroscopy, vol. 70, 2016, pp. 27-41

- VERnet, J. L.; OgEREAU, P.; FIGUEIRAL, I.; MACHADO, C.; UZQUIANO, P. (2001) Guide d'identification des charbons de bois préhistoriques et récents. Sud-Ouest de l'Europe: France, Péninsule Ibérique et îles Canaries. Paris: CNRS, 2001 